\title{
Role Positioning for College Oral English Teachers
}

\author{
Lv Xin \\ Foreign Language Department \\ Jilin Business and Technology College \\ Changchun, China \\ 182076127@qq.com
}

\begin{abstract}
Along with the rapid development of international contacts, English reading and writing can not meet the requirements of people; they need to improve spoken English skills. It's an issue for oral English teachers how to organize a successful oral lesson. At present, in terms of oral English of college students in China, there are still problems in communication skill. One of them is role positioning for oral English teachers. The aim of oral English teaching lays an emphasis on improvement of students' oral expression ability and learning ability, while neglecting the importance and influence of teachers' role positioning. In English teaching activities, the teachers' role positioning should consider the features and effects of various factors, including teaching content, teaching objective, teaching resource, and teaching mode, etc. The teachers' roles differ with different teaching objectives under different environments. Therefore, it's the current problem for college oral teachers to improve the ability of students' oral English from the perspective positioning the role and changing the teaching mode. This paper mainly explores the teachers' role positioning from the three aspects---creators for language environment, planners for class teaching activities, instructors of language expression and the motivator of non-intelligence of students to adjust the teaching mode and improve the student's oral spoken ability.
\end{abstract}

Keywords-oral English teacher; creator; planner; insturctor; motivator

\section{INTRODUCTION}

Under the background of globalization, relations between nations become closer, and international communication becomes increasingly frequent. Nowadays, English learning is not just to satisfy the demand of English reading and English writing for college students. What is more emphasized is the improvement of oral English ability. As a result, how to improve the quality of college oral English teaching has become a pressing problem for college oral English teachers. In consideration of the past teaching mode, lectures on theoretical knowledge are the main class teaching activities. However, oral English teaching is different from other kinds of teaching, which highlights the practice of language expression. Therefore, more chances for self-expression and practice should be provided to students. Efficient oral English class teaching should help students practice a lot and improve their oral expression ability under scientific guidance and instruction of the teachers, within a limited time and space. In order to improve the teaching quality, oral English teachers need to properly define their roles in teaching activities.

\section{A BRIEF ANALYSIS ON BASIC CONTENTS OF THE TEACHERS’ ROLE}

Roles are individuals in certain social position, who are adapt to the social environment and have their unique behavior pattern according to the objective of social expectations based on their subjective ability. The roles of teachers refer to the behavior pattern according with the social expectation determined by their special status in the educational system. The teachers' behavior instructed by teacher roles is the "role behavior" of teachers. Under the new situation of college English reform, what we need to study further is what roles the college English teachers play, because it relates to the success of reform.

Of course, misunderstandings in cognition are inevitable in the roles conversion between traditional roles of teachers and new ones. What highlights is some of the teachers have conflicted emotions to the "students-centered" teaching conception, thinking that this kind of teaching diminish the teachers' position and roles.

During the learning process of any language, there are five basic factors including teacher, student, textbook, teaching activity, and teaching objective. The teaching aim could be achieved through effective connection and combination of the five factors. Change of any factor will influence the other four factors, and finally influence the completion of teaching tasks.[1] The aim of oral English teaching lays an emphasis on improvement of students' oral expression ability and learning ability, while neglecting the importance and influence of teachers' role positioning. In English teaching activities, the teachers' role positioning should consider the features and effects of various factors, including teaching content, teaching objective, teaching resource, and teaching mode, etc. The teachers' roles differ with different teaching objectives under different environments.

First, teachers are observers of students' individuality. Teachers should carefully observe and analyze students' individual interest, strength, hobbies and learning ability. Second, teachers are planners of class. They are responsible for the arrangement and design of teaching activities, lectures on teaching contents, and plan of teaching schedule. Third, teachers are editors of the textbooks. Teachers need to arrange teaching contents according to the time, schedule, and aim of the teaching activities. Fourth, teachers are problem-solvers of students. Teachers should not only help students solve problems in learning but also care about students, to enable 
them to involve in learning activities with the best condition. Fifth, teachers are facilitators. Teachers with a high teaching level are liable to help less qualified teacher to make common progress and improve the overall education level. Sixth, teachers are promoters to cooperation. Besides class teaching, teachers should establish a favorable relationship with the students to enable them involved in teaching activities. Seventh, teachers are explorers. Teachers should continuously explore the professional knowledge in specific field and promote development of relative studies. Eighth, teachers are participants of scientific research. College teachers should possess a certain capability of scientific research. They should continuously enlarge their professional knowledge to promote development of scientific research in relative fields. [2]

It can be seen that in college oral English teaching, the teachers' role is not just the same and always fixed. In practical teaching process, teachers should consider each relevant factor, and scientifically position and adjust their own roles according to the actual teaching requirements, in order to improve students' oral English abilities. This paper mainly explores the oral English teachers' roles from the following four aspects.

\section{ORAL TEACHERS ARE CREATORS FOR LANGUAGE ENVIRONMENT}

If the students have sufficient time and condition to practice oral English, their oral expression ability could be improved to a larger extent. The problem is how to create more chances for students to practice oral English. That means that teachers should not only give students a certain opportunities, but also create proper language environments for students to practice oral English. English is not our native language and we are used to Chinese language environment in our daily life, which is an important factor that limits the improvement of oral English. Therefore, it is necessary for teachers to create proper language environments in usual teaching activities.[3]During the real teaching process, teachers should encourage students to communicate with each other in English, answer questions and express their own ideas in English. Even if their oral expression is not so frequent or correct, at least an atmosphere for English speaking has been created to motivate students to try to speak English. It can help improve students' enthusiasm on improving oral English, and effectively improve their listening and speaking abilities at the same time. Eventually students will be used to understanding and communicating by means of speaking English, so that the fluency and accuracy of their oral English could be gradually improved. However, a high quality language environment is not easy to be created. Thus, teachers can make use of simulative living situation in teaching to improve the quality of language environment. A relatively real situation is able to effectively help students to apply language into the real life so as to improve the practical application of English. During the teaching process, teachers could create a simulative living situation, to let students communicate in English through role-play. Take the following teaching situation as an example, there are some tourists visiting a scenic spot. Because they are not familiar with the route, they need to ask local people. In this case, teachers could ask several students to play as the tourists, and ask several students to play as local people. They are supposed to practice how to ask the way and how to respond. For example, "Excuse me? Do you know where the bus stop is?" "What can I do for you?".

Other than creating simulative living situations, oral English teachers should continuously enrich their knowledge related with linguistics and cultures of English-speaking countries. If students are confused about the cultural difference, teacher should be able to make explanations. Successful teachers could not just teach the knowledge of this subject, but improve students' awareness and spiritual level. Students should understand the culture beyond language expression, if they want to genuinely be good at speaking English. For example, in an English-speaking country, if you are praised by a local person as "You are so beautiful!", a Chinese person is likely to respond "No, I am not beautiful." That's because Chinese people are accustomed to respond such compliment in a modest way. But in western culture, they would like to say “Thank you!". In addition, teachers should stress emphasis on extension of students' knowledge base to broaden their horizon. In another word, oral English teachers should not only make effort to create language environment and teaching situation, but also create the cultural atmosphere.

\section{Oral Teachers Are Planners For Class TeAching ACTIVITIES}

Teachers are planners who are in charge of the whole class teaching activities, so they should be capable of planning and managing activities. Apart from teaching activities for writing, listening and reading classes, oral English teaching is likely to involve more teaching activities. [4]Such activities are students-centered, which are aimed at oral practice. Compared with other kinds of English teaching, oral English teaching is more challenging. The role of planners for class teaching activities can be reflected in many aspects. It is noted that the planning of class teaching activities is not simply arrangement and implementation of teaching contents, instead, it should enable all students to learn something and achieve the purpose of the activities based on a general control of schedule and order of the activities. In fact, whatever roles the teachers play in teaching activities will have a different impact on students' learning. Therefore, teacher should make good use of interaction and communication with the students. For example, when a teacher organizes a group activity in class, the teacher should firstly give a clear introduction to the rules of activity and encourage every student to participate in the activity. When the activity begins, the teacher needs to carefully observe and control the details and development process of the activity, to see whether there are factors limiting the activity, whether there are students not participating in the activity, and whether students are following the rules of activity. While a student is making a speech in class, the teacher cannot let the student speak freely without control. Instead, the teacher should reasonably control the time of speech and make each activity meaningful and helpful for teaching. During the activities, the basic task for teachers is to make every student involved to ensure students' participation, as well as supervise and control students' performance in these activities.[5] Teachers should control the schedule and keep the activities in track, so that the purpose of such activities could be achieved. What's more, in order to improve the applied value of class 
teaching activities, teachers should make an analysis and conclusion on the teaching effect of each activity, for the purpose of better planning of future activities. Besides, other factors could be considered in planning of class activities, including the form of activities, students' enthusiasm, and effectiveness of the activities, etc. Teachers need to get along well with the students. They should be patient to respond to the students who are not so clear with the detail of activities, as well as provide guidance for effective practice. For example, the teacher could ask such students to learn from other students with excellent performance and make summary and record on the activities.

\section{ORAL TEACHERS ARE INSTRUCTORS OF LANGUAGE EXPRESSION}

In teaching activities, oral English teachers should not only control the whole activity, but also pay attention to the accuracy of students' language expression. To some extent, error is actually a kind of resource in teaching. Teachers can make use of the errors in students' expression as a case study to make explanations and amendments, as well as test the effectiveness of students' learning. From the perspective of teachers, teachers could reflect on student's errors in expression, and accordingly adjust their teaching contents and highlighting points; on the other hand, from the perspective students, correction of the errors could make students' oral expression modified, so as to help improve student's practical ability of oral English.[6]

In consequence, teachers should pay attention to guide student's oral expression and timely correct the errors. Different from English writing training, errors in oral English are not just related with grammar and vocabulary but also connotation and pronunciation, etc. Such errors can only be easily found in oral expression, because in writing training, students are able to check and modify their own writing, while students are concentrated on the contents they want to say along with organization of language, so it is more difficult to find their own errors in oral practice. Therefore, teachers need to play as the error corrector to help students find their errors and make timely modification and guidance. However, it is worthy to consider that teachers should not hurt students' confidence when pointing out their errors. Some teachers think that the errors need to be corrected as soon as the errors occur, while some other teachers believe that the errors should be corrected after the teaching activity. It is common that different people hold different attitudes. In fact, what is the best way needs to be considered and analyzed based on the actual situations and the form of teaching activities.

\section{MOTIVATOR OF NON-INTELLIGENCE FACTOR OF STUDENTS}

Speaking is the unity of cognitive, emotional, symbolic and power system. For a long time, Chinese culture has always been closed, which has rare exchanges with the outside world. English as a foreign language has been strange to the Chinese people; therefore, people are cautious, timid and conservative when they speak English. To some extent, it's very important for Chinese to overcome the mind when they speak English.
It's shown by the psychology that psychology block plays a very important role in speaking English. Therefore, it's a problem faced by the college English teachers about how to adjust their mind, motivate students' non-intelligence factors, and develop a positive and open mental communication environment in college English teaching.

Krashen(1982) inherited and developed the "affective filter theory", who points out that the learners' motivation, selfconfidence and anxiety plays the positive or negative role in the input of language into the organs of brain. If the learner has obvious motivation and strong confidence, less anxiety, he may accept more language input and have a better effect. So, it's a precondition and better guarantee for language input to create a relatively low communication circumstance of "affective filter". In contrast, language output is the nature of oral English teaching; speaking and speaking correctly is the best state of oral English teaching. It's very important for the students to keep a good state of non-intelligence.

Most of the college students have obtained the relevant language knowledge, but various psychology blocks stop the further learning and improvement of the language, especially in speaking. Speaking is the two-way and positive communication activities between the speaker and listener. Such communication requires the speakers "expose" completely in front of other speakers, just like the actors perform on the stage, which causes the psychological pressure or challenge. Most of the students are afraid that they may make mistakes in communication and they are unwilling to speak in the public, losing the chance of speaking. Consequently, their speaking consciousness and ability are restrained to a large degree.[7]

During the teaching activities, oral English teaching should create relatively low "affective filter" language circumstance in view of the qualities of non-intelligence of the students. Teachers should construct relaxed and harmonious classroom atmosphere and mobilize the internal emotion factors fully. Ausubel pointed out that motivation can promote learning by strengthening the behavior and in turn what the learners have obtained can stimulate the motivation of learning. The teachers should encourage the students to speak bravely to arouse the learning enthusiasm and make them feel the happiness of successful expression. The teachers should adopt the emotion teaching principle and forgive the mistake of their speaking to get rid of the psychological pressure, which reaches the point of "I am asked to speak" to "I want to speak".

\section{CONCLUSION}

It can be found from the above analysis that the role of teachers in teaching activities is not always fixed, but varies according to different teaching objectives, teaching tasks, and teaching conditions, etc. Except for adjusting their role according to actual situation, sometimes teachers may play several roles at the same time. What's more, teachers are supposed to enrich their English knowledge, and continuously improve their professional quality as well as their teaching ability, to promote the smoothness of oral English class activities. Successful oral English teachers should be careful about each teaching step including setting teaching objectives, 
making teaching plans, choosing teaching contents, and implementing teaching activities, etc. as well as adopt scientific teaching methods to accommodate class teaching based on actual demands. Therefore, in order to make the whole oral English teaching process effective, oral English teachers should be used to making summaries and reflections on daily teaching activities, and arrange the subsequent teaching activities as well as adjust teaching plans according to students' learning state and their oral English abilities.

\section{REFERENCES}

[1] Tan Zhuyang. Transformation on the Teachers' Roles in Oral English Classes after Reform of College English Teaching[J]. Human Resource Management (Academic Edition), 2010,(5):145-145.
[2] Wang Jing. Reform of Test Mode of College Oral English and Transformation on Teachers' Roles[J]. China Education Innovation Herald, 2013,(13):218.

[3] Shan Ying. Oral Teaching in College Class Teaching[J]. Times Education (Education and Teaching Edition), 2012,(9):155-156.

[4] Fang Meixiang. A Brief Analysis on Teachers' Roles in Oral English Teaching[J]. Science \& Technology Information, 2014,(9):98,103.

[5] Zhu Yayun. Reconsidertion of Role Position of teachers in College English Teaching[J]. Journal of Anhui Agricultural University,2008.5:70-73.

[6] Zhou Yana. On the Role Posotioning of Teachers in College English Lesson, Journal of Hei Longjiang Education College, 2015,(5):90-100

[7] Deng Chunxia. On the Role Positioning of College Englsih Teahers[J] Journal of Chong Qin university (Social Science Edition)2004.06. 